\title{
Practice and Exploration of Curriculum Ideological and Political Education in the Construction of Online Courses in Medical Universities
}

\author{
Bo Ling1*, Jie Wang2*, Kaifen Liang1, Ying Zhang1, Zhongwei Zhang1, Guangbin Ye1, \\ Xianjiu Liao\#, Xuebin Li1" \\ ${ }^{1}$ Youjiang Medical University for Nationalities, Baise, China \\ ${ }^{2}$ Youjiang Medical University for Nationalities Affiliated Hospital, Baise, China \\ Email: "lxj2006910@163.com, "yyfylxb126@126.com
}

How to cite this paper: Ling, B., Wang, J., Liang, K. F., Zhang, Y., Zhang, Z. W., Ye, G. B., Liao, X. J., \& Li, X. B. (2021). Practice and Exploration of Curriculum Ideological and Political Education in the Construction of Online Courses in Medical Universities. Creative Education, 12, 865-870. https://doi.org/10.4236/ce.2021.124062

Received: January 21, 2021

Accepted: April 23, 2021

Published: April 26, 2021

Copyright $\odot 2021$ by author(s) and Scientific Research Publishing Inc. This work is licensed under the Creative Commons Attribution International License (CC BY 4.0).

http://creativecommons.org/licenses/by/4.0/

(c) (i) Open Access

\begin{abstract}
Objective: Explore new methods and functions of ideological and political education in the construction of online courses. Methods: Taking the construction of the online course of Chinese medicine pharmacology as an example, the necessity of ideological and political education in the construction of online course is analyzed. At the same time, combined with the disciplinary characteristics of traditional Chinese medicine pharmacology, it analyzes the new methods and effects of ideological and political education integration. Results: Ideological and political education integrates the construction of online courses, which can be integrated into the foreword of the times, models of the times, cutting-edge technology and professional cases, so as to enhance students' patriotism, ideological morality, innovative thinking and professional skills. Conclusion: Ideological and political education runs through the construction of online courses, so as to provide new ideas for the training of students majoring in Chinese pharmacy.
\end{abstract}

\section{Keywords}

Curriculum Ideological and Political Education, Information-Based

Teaching, Online Course Construction, Medical Universities

*These authors contributed equally to this work.

\#Corresponding author. 


\section{Introduction}

Pharmacology of Traditional Chinese Medicine is a professional basic course for students majoring in Traditional Chinese Pharmacology. It is an important subject for the modernization of traditional Chinese medicine industry ( $\mathrm{Fu}, 2020)$, involving Pharmacology, Traditional Chinese Medicine, Cytobiology, Molecular Biology, Pathology and so on. Among the teaching reforms of Pharmacology of Traditional Chinese Medicine, reforms of online courses focus on the characteristics of the teaching mode, such as portability, repeatability and wide-range audiences. However, few reforms have been seen highlighting curriculum ideological and political education (Gong, Juan, Hu, and Wang, 2018). Curriculum ideological and political education is a kind of comprehensive education concept, which constructs the whole staff, the whole process and the whole curriculum education pattern, forms the synergy effect between all kinds of courses and ideological and political theory courses, and takes "moral cultivation" as the fundamental task of education. As the soul of college education, curriculum ideological and political education indicates a major direction for the cultivation of students majoring in Traditional Chinese Pharmacology, and serves as the cornerstone of the development of Pharmacology of Traditional Chinese Medicine (Li, Zhang, Liu, Han, Lin, Li, Wang, Dai, Guan, \& Bao, 2020). The course of Ideological and political education can start from moral education, professional quality and professional quality to comprehensively and systematically cultivate the comprehensive ability of TCM talents. Therefore, promoting online course construction from the perspective of curriculum ideological and political education is the inevitable trend of the teaching reform of Pharmacology of Traditional Chinese Medicine.

\section{Necessity of Curriculum Ideological and Political Education in the Construction of Online Courses of Pharmacology of Traditional Chinese Medicine}

Traditional Chinese medicine (TCM) is an important part of modern medicine in China. It is the general name of the medicine of all ethnic groups in China, including the medicine of the Han nationality and the medicine of the minority nationality. It reflects the Chinese nation's understanding of life, health and disease, and has a long history and unique theory and technology.

The development of traditional Chinese medicine must be in line with China's national conditions. At the same time, it needs talents with noble morality and excellent professional quality. The integration of curriculum thought and politics and Internet can cultivate students to establish correct professional values by combining knowledge imparting, ability training and value guidance through the concept of all-round education (Huang, 2019). The innovative teaching mode of "combination of Internet and ideological and political education" can be designed from the aspects of Ideological and political education objectives, ideological and political entry points, ideological and political elements, education methods and professional carriers, to enhance students' overall professional 
thinking and vision (Chu \& Zhou, 2021). In the cultivation of TCM talents with both ability and political integrity, the integration of morality and specialty is one of the core directions of TCM higher education reform. Pharmacology of Traditional Chinese Medicine, as the core professional course of the TCM major, is an interdisciplinary subject. It is the basis for the clinical modernization of the TCM industry. The traditional classroom teaching mode has certain limitations in knowledge comprehensiveness, depth and acquisition, which leads to learning difficulties of students and unsatisfactory teaching effect of teachers (Chen, Yang, Zhao, Zhang, \& Zhao, 2019). Therefore, the development of web-based education to promote online courses has become a new way to solve the above problems. However, the construction of online courses shall be guided by curriculum ideological and political education, so as to support the cultivation of TCM professionals with patriotism, dedication, excellent skills and innovative thinking. Only in this way can we finally promote the realization of TCM modernization (Pan, Chen, Fu, Gan, \& Shen, 2018). Therefore, it is necessary to carry out online course construction guided by the curriculum ideological and political education during the teaching reform of Pharmacology of Traditional Chinese Medicine.

\section{Design of Online Courses of Pharmacology of Traditional Chinese Medicine Based on Curriculum Ideological and Political Education}

1) Enhance students' patriotic feelings based on the historical background

During online course construction, we should highlight the hot spots of the times to ensure the instructive teaching content and increase students' learning interests (Tang, Yue, Yang, \& Kang, 2020). The contemporary significance of the TCM industry shall be underlined during the online course construction for Pharmacology of Traditional Chinese Medicine, especially the outstanding results of TCM in the prevention and control of COVID-19. In the prevention and treatment of COVID-19, Chinese patent medicines such as Lianhua Qingwen Capsule, Shufeng Jiedu Capsule, Jinhua Qinggan Granule, and TCM prescriptions have made highlighted contributions (Xu, Dong, Tu, Zhang, Liu, Zhang, \& Huang, 2020; Shen, Fu, Wu, Kuang, Li, Zhu, Zhao, Xia, Chen, Guo, \& Lai, 2020; Duan, Xia, Zheng, Sun, Li, Li, Li, Zhang, Zhang, Zhang, \& Liu, 2020). In the online course design, the Chinese patent medicines with prevention and treatment effect shall be, according to the characteristics of the COVID-19 prevention and treatment, integrated into the teaching of the pharmacological effect and clinical application of heat-clearing medicine, Such as: the antiviral effect of Forsythia suspensa in Lianhua Qingwen capsule, Banlangen in Shufeng Jiedu Capsule and Honeysuckle in Qinggan granules of Jinhua, so that the students, with enhanced national confidence and patriotism will be determined to contribute to the development of TCM.

2) Edify students' ideological and moral character with model of the times

When constructing the online courses of Pharmacology of Traditional Chi- 
nese Medicine, we should highlight the meritorious deeds and noble spirits of the models of the times and introduce them into the classroom, to edify the students' ideological and moral characters and cultivate successors with both ability and political integrity for the new era. For example, Wang Yiping, a researcher of Shanghai Institute of Materia Medica, Chinese Academy of Sciences, is honored as a "Model of the Times". He has been committed to the exploration of Salvia miltiorrhiza, a drug for promoting blood circulation and removing stasis, and developed a new product "Salvia Miltiorrhiza Polyphenol Hydrochloride Powder Injection” with remarkable clinical effect (2019). The deeds of Wang Yiping can be introduced into the teaching of pharmacological effects in the key chapter "Drugs Promoting Blood Circulation and Removing Stasis" during the online course construction for Pharmacology of Traditional Chinese Medicine, especially the process of research and development, to help the students to develop the spirit of pursuing truth and serving the country. Huang Wenxiu, another "Model of the Times", made outstanding contributions in the front line of poverty alleviation (Wang \& Luo, 2020). When constructing the online courses of Pharmacology of Traditional Chinese Medicine, the story of Huang Wenxiu leading Baini Village people to plant star anise can be integrated into the pharmacological effect and clinical application of aromatic dampness-resolving medicines, highlighting the value of traditional Chinese medicine industry in practical application to students, to help the students to develop the spirit of serving the people and being passionate in their jobs.

3) Cultivate students' innovative thinking with technological elements

Technology is one of the major forces to promote the rapid development of TCM, and one of the fundamental elements for the discipline construction and development of Pharmacology of Traditional Chinese Medicine. Xi Jinping, general secretary of the CPC Central Committee, chairman of PRC and chairman of the Central Military Commission, made important instructions on TCM industry, requiring us to inherit the essence, keep innovative and contribute to the construction of a healthy China. Therefore, it is necessary to highlight technological innovation in the online course construction of Pharmacology of Traditional Chinese Medicine. Tu Youyou, a 2015 Nobel Prize winner, devoted all her life to the research of Artemisia apiacea, a heat-clearing medicine, and developed artemisinin for the treatment of malaria (Bai \& Tu, 2020). The research and development of artemisinin by Tu Youyou can be integrated into the teaching of the pharmacological effects of heat-clearing medicines, especially the anti malaria effect and clinical characteristics of artemisinin, when constructing the online courses of Pharmacology of Traditional Chinese Medicine, which will help the students to develop scientific and innovative thinking.

4) Improve students' professional skills through professional cases

Pharmacology of Traditional Chinese Medicine is a core professional basic course of TCM, and also the guiding discipline for the development of the TCM industry. The core knowledge system and professional skills involved in this discipline are the foundation of the students' future career development. In order to 
highlight the practical application of Pharmacology of Traditional Chinese Medicine, the knowledge system and skills involved can be united into the online course construction. Therefore, the theoretical knowledge and technical system of Pharmacology of Traditional Chinese Medicine applied in drug research and development by TCM enterprises, clinical efficacy evaluation by hospitals, and drug testing by drug control institutes can be introduced into the online course construction, especially, key technologies such as animal model, pharmacodynamics evaluation, toxicological evaluation, metabolic dynamics analysis, to improve students' professional skills generally.

In the construction of the online course of pharmacology of traditional Chinese medicine, aiming at the discipline characteristics of pharmacology of traditional Chinese medicine, combining with the ideological and political system of the course, the network course is expanded and extended around the preface of the times, the model of the times, the preface of science and technology, and professional cases, so as to enhance the students' patriotic feelings, ideological and moral character, innovative thinking and professional skills.

\section{Conclusion}

In the course construction of the network course of pharmacology of traditional Chinese medicine, it can integrate the list and idea of curriculum thoughts and politics, promote the combination of moral education and professional training of students, so as to effectively improve the cultivation of high-level talents of traditional Chinese medicine.

\section{Fund Program}

Undergraduate Teaching Reform Project of Guangxi Higher Education (Project No.: 2018JGZ132, 2019JGZ138, 2018JGA237); Innovation Project of Guangxi Postgraduate Education (Project No.: JGY2021214).

\section{Conflicts of Interest}

The authors declare no conflicts of interest regarding the publication of this paper.

\section{References}

(2019) Propaganda and Education Bureau of the Publicity Department of the Communist Party of China, National Print Media Public Service Advertising Production Center of People's Daily, Promoter of Modernization of Chinese Traditional Medicine-Wang Yiping, Researcher of Shanghai Institute of Materia Medica, Chinese Academy of Sciences. Teaching Examination, No. 32, 81.

Bai, X. Y., \& Tu. Y. Y. (2020). Different Story, Extraordinary Achievements, Re-Observation of the Health Superstar. Health China Observation, No.1, 36-40.

Chen, Z. Z., Yang, X. W., Zhao, T., Zhang, N., \& Zhao, H. (2019). Construction and Practice of Pharmacology of Traditional Chinese Medicine Online Course Based on BB Platform. Health Vocational Education, 37, 23-24. 
Chu, C. J., \& Zhou, J. F. (2021). Teaching Design and Innovation of "Internet Plus Ideological and Political Education" for Environmental Courses. Journal of Higher Education, No. 10, 82-85.

Duan, C., Xia, W. G., Zheng, C. J., Sun, G. B., Li, Z. L., Li, Q. L., Li, P., Zhang, H. L., Zhang, F. W., Zhang, B. L., \& Liu, Q. Q. (2020). Clinical Observation of the Treatment of Light COVID-19 Cases with Jinhua Qinggan Granule and Conventional Western Medicine Treatment Plans. Journal of Traditional Chinese, 61, 1473-1477.

Fu, H. (2020). Exploration and Research on the Integration of Ideological and Political Elements in Online and Offline Teaching of Traditional Chinese Pharmacology. China Journal of Multimedia \& Network Teaching (Midmonth Issue), No. 12, 108-110.

Gong, M., Juan, J. Z., Hu, X. G., \& Wang, Y. F. (2018). Application of Micro-Course in the Teaching of Pharmacology of Traditional Chinese Medicine. Phamacy and Clinics of Chinese Materia Medica, 9, 56-57.

Huang, X. (2019). A Probe into Teaching Practice of "Internet + Ideological \& Political Theory Teaching in All Course" in International Trade Major in Vocational College. Theory and Practice of Education, 39, 24-26.

Li. L. J., Zhang, Y. J., Liu, J., Han, D., Lin, H., Li, Y. M., Wang, C. Y., Dai, L. B., Guan, W. C., \& Bao, H. W. (2020). Discussion on the Path of the Teaching Reform of Pharmacology of Traditional Chinese Medicine and the Integration of Ideological and Political Education. Education Modernization, 7, 42-45.

Pan, D., Chen, Y., Fu, L. Y., Gan, S. Q., \& Shen, X. C. (2018). Primary Exploration of the Construction and Application of Pharmacology of Traditional Chinese Medicine Online Course: A Case Study of Guizhou Medical University. New West, No. 23, 44-45.

Shen, F., Fu, Z. Y., Wu, Y. R., Kuang, G. Y., Li, L., Zhu, K. M., Zhao, Y. D., Xia, Y., Chen, W., Guo, Y. M., \& Lai, Q. L. (2020). Research of the Potential Targets and Mechanisms of Shufeng Jiedu Capsule in Treating COVID-19 Based on Network Pharmacology and Molecular Docking Technology. Guiding Journal of Traditional Chinese Medicine and Pharmacology, 26, 8-15+22.

Tang, Y. L., Yue, W., Yang, Y. Y., \& Kang, J. J. (2020). Reflections on Online Course Education. Science and Technology \& Innovation, No. 24, 62-63+67.

Wang, J. S., \& Luo, M. (2020). Remaining True to the Original Aspiration and Make the Glorious Youth Meaningful: Huang Wenxiu, “A Model of the Times”. Knowledge Is Power, No. 11, 72-73.

Xu, X. H., Dong, H., Tu, S. H., Zhang, M. M., Liu, D., Zhang, H. Q., \& Huang, G. Y. (2020). Retrospective Analysis of Treating Common COVID-19 Cases with Honeysuckle Detoxication Granule and Lianhua Qingwen Capsule. Research of Integrated Traditional Chinese and Western Medicine, 12, 383-386+389. 